\title{
GENETIC PARAMETERS OF LITTER WEIGHT TRAITS OF APRI RABBITS IN EGYPT
}

\author{
N.S. Hassan ${ }^{1}$, A.M. Abdel-Ghany ${ }^{2}$ and H.M. Sabri ${ }^{2}$
}

1- Animal Production Research Institute, Agriculture Research Center, Ministry of Agriculture, Egypt, 2- Animal Production Department, College of Agriculture, Suez Canal University, AlIsmailia, Egypt

\section{SUMMARY}

Litter weight traits, (LW at birth; 21 and at weaning at 35 days post kindling), for two consecutive years on APRI rabbits (a synthetic line derived from the maternal Spanish V-line and the Egyptian Baladi Red breed), were genetically evaluated. The data of litter weights (at birth, LWB; at 21 days, LW21 and at weaning, LWW) contained a total of 192 litters produced from 80 does pedigreed by 9 sires and 12 dams, were analyzed using Multi Trait Derivative Free Restricted Maximum Likelihood Animal Model (DFREML). The Mathematical model of the analysis comprised the effects of yearseason combinations (YRS) and parity $(P)$ as fixed, as well as animal and uncorrelated permanent environmental effect as random effect.

Heritabilities of the considered doe traits were relatively low being 0.17, 0.04 and 0.11 for litter weights at birth; 21 days and weaning; resp. Furthermore, estimates of uncorrelated permanent environmental effects were rather low being 0.2, 0.002 and 0.008 for litter weight at the same manner. From the previous heritability estimates, it can be concluded that family or within family selection could be more effective and valuable than individual selection to improve these traits of APRI does' rabbits under the Egyptian North-Delta climatic conditions.

The ranges of the APRI does' transmitting ability $(T A \pm S E)$ for $L W B, L W 21$ and LWW were $(0.152$ $\pm 0.020,0.340 \pm 0.050$ and $1.167 \pm 0.180 \mathrm{Kg}$.) with the accuracies being 0.350, 0.340 and 0.184.As for $A P R I$ dams' transmitting ability $(T A \pm S E)$, the ranges for $L W B, L W 21$ and $L W W$ were $0.09 \pm 0.03,0.2$ \pm 0.07 and $0.7 \pm 0.03 \mathrm{Kg}$. with the accuracies being 0.84, 0.83and 0.84; resp.

Similarly, the ranges of APRI sires' transmitting ability (TA $\pm S E)$ for LWB, LW21 and LWW were $0.11 \pm 0.02,0.24 \pm 0.06$ and $0.81 \pm 0.19 \mathrm{Kg}$ with the accuracies being $0.51 \%$ for all litter weight traits. Interestingly, and though of the larger numbers involved, ranges of accuracies estimates $\left(r_{A P}\right)$ of the predicted breeding value $(B V)$ of APRI rabbits were mostly higher in the dams data set followed by those of does.

The estimates of correlation, however, were age dependent and decreased as age advance, indicating correlated response to selection that should be considered in selection plans. Selection for LW may not be practically and realistically associated with a correlated improvement in the later-ages does' performance which in turn may have its impact on generation intervals and relatively amplify and enlarge selection costs.

In addition, estimated epigenetic trends (EP), for litter weight traits under study suggested that it is possible to achieve slow, but simultaneous improvement of litter traits with selection program in rabbits. LW traits recorded generally a negative EP trend during the majority of the year-seasons under study. However as regard to EP with parities, the high LW response was postponed to the later parities.

\section{Keywords: rabbits, litter weight, heritability estimates, variance components, epigenetic trend}

\section{INTRODUCTION}

Genetic improvement of Egyptian rabbits for economically important traits, particularly doe litter traits, is an important component of an expected overall strategy to improve profitability and sustainability of broiler rabbits operations. Characterization factors that affect short and long-term genetic improvement, selection, and mating strategies in a population is essential to construct and then evaluate genetic improvement programs and determine areas that need to be amended and improved. The retarded or small genetic changes for rabbit doe litter traits under nation production suggest that selection and mating strategies used for genetic improvement in Egyptian rabbit populations had limited success. However, these population estimates of genetic trends provide no information on adaptation process and epigenetic trends that occurred within individual levels of environmental circumstances.

The Egyptian animal breeds, including native rabbit ones, are supposed to be a part of our national genetic resources' wealth that must undergo more research and improvement, first to preserve them and second to reveal their distinguishing characteristic features and to promote them to compete with the exotic ones. It is therefore, the accurate determination of 
rabbits' genetic parameters and breeding values for most economic traits, of such populations, are essential for planning and to achieve success in their breeding plans and programs. Litter traits are of the utmost and supreme cost-effective prolificacy traits of the rabbit doe. Youssef et al., (2008) reported that a selection program for broiler rabbits is being carried out in three Egyptian and one Saudi Arabian research centers, each of them having the task to develop lines of rabbits in their local conditions, in which efforts were assembled to develop new lines of meat rabbits, where heat stress is considered as one of the most important limiting factors to raise meat rabbits in these areas. One of these lines is the APRI line originated from the Spanish V line crossed with our local Baladi Red line, the synthetic APRI line is composed of 50\% from the line $\mathrm{V}$ and $50 \%$ from the Baladi Red rabbits.

Performances obtained verified that the most stable and convenient trait in all synthetic lines influenced by line $\mathrm{V}$ is referring to the prolificacy, which has been around 9.0 total born, 8.5 born alive and 7.2 number weaned per litter in the majority of the locations. Postweaning daily gains were also convenient and ranged from 18 - $34 \mathrm{~g} /$ day in different locations studied, Youssef et al. (2008).

Crossing between exotic and local breeds can be done to take advantage of the existent heterosis or hybrid vigor (Youssef, 1992) and genic complementary effects (Abdel-Ghany et al., 2007) in the majority of economic traits.

In 2003, a co-operative rabbit crossbreeding project was established between Egypt and Spain to establish a new maternal line of meat rabbits suitable for hot climate. V-line females rabbits used in this project were crossed with males of Baladi Red (BR) rabbits.

This paper outlines a Derivative-Free REML Animal Model Algorithm to estimate the variance components; genetic parameters and BLUP values of the Litter weight (LW) traits in APRI rabbits.

\section{MATERIALS AND METHODS}

APRI, maternal line rabbits is a rabbit line which is reared in Sakha and Gemmeza experimental Rabbitery, Animal Production Research Institute, Agricultural Research Center, Ministry of Agriculture, Egypt, Field records Data of APRI line collected through two consecutive years $(2008$ - 2009) on doe litter weight traits at birth; 21 days and weaning at 35 days post-kindling were used in this study. Breeding does and bucks were lodged separately in individual collective galvanized wire cages arranged back to back in single tier batteries provided with feeders and automatic nipple drinkers. Rabbit does houses were provided with nest boxes at 25 days after fertile mating. All rabbits were fed on the same commercial pelleted diet containing approximately $18 \%$ protein, $2.39 \%$ crude fat and $12.8 \%$ crude fiber. Feed and water were provided all the day long. Weaning of litter was done five weeks after kindling. Cages of entire group of animals were cleaned and disinfected regularly before each kindling. All through the experimental period, animals were medicated likewise and subjected to harmonious managerial and environmental conditions.

Breeding plan started in October 2008 and terminated at the end of spring 2009. Litter weight (LWB, LW21 and LWW) at birth, 21 and weaning at 35 days post kindling were recorded. For breeding, each doe was transferred to the cage of its assigned buck to be bred, and palpated 10 days later, for successful pregnancy testing. Does that failed to conceive were returned to the same assigned buck to be rebred. Nest boxes were prepared for parturition with saw dust in the 25th day of the pregnancy.

Numbers of sires, does and dams along with number of litters are listed in table 1.

\section{Statistical and genetic analysis:}

Starting mixed model procedure (Co) variance matrix, for every studied age (birth, 21 days post kindling and at weaning) of the litter weight traits were obtained applying REML method of VARCOMP procedure of SAS, 2003. These starting values were used for the estimation of the more precise and reliable estimates of multi trait animal model variance and covariance components.

Data of does litter weight traits were analyzed using DFREML of Boldman et al. (1995). The model adopted for analyzing the data comprised the effects of year-season combinations and parity effects (as fixed effects), in addition to the additive genetic and permanent environmental (as an uncorrelated random effect).

The following animal model (in matrix notation) was used:

$$
\begin{aligned}
& y=X \boldsymbol{b}+Z_{a} \boldsymbol{u}_{a}+Z_{c} \boldsymbol{u}_{c}+\boldsymbol{e} \\
& \text { Where: }
\end{aligned}
$$

where $\boldsymbol{y}=$ vector of observations on animal for does litter weight at birth, 21 and at weaning at 35 days post kindling (LWB, LW21 and LWW); $\boldsymbol{b}=$ vector of unknown fixed effect peculiar to year-season (5 levels); $\mu_{\mathrm{a}}=$ vector of random additive genetic effects of the animal for the $i^{t^{\text {th }}}$ trait; $\boldsymbol{U}_{\boldsymbol{c}}=$ vector of random permanent environmental effect (doe-parity combination); e= vector of random error; $\boldsymbol{X}, \boldsymbol{Z}_{\boldsymbol{a}}$ and $\boldsymbol{Z}_{\boldsymbol{c}}$ are incidence matrices relating records of $i^{\text {th }}$ trait to the fixed, random animal and random permanent environmental effects; resp. $r \wedge_{A \mathrm{i}}=$ the accuracies of the prediction of the $i^{\text {th }}$ animal's breeding 
value; $F_{j}=$ inbreeding coefficient of animals (assumed to be zero in case of unknown pedigrees); $\mathrm{d}^{\mathrm{j}}=$ the $\mathrm{j}^{\text {th }}$ diagonal elements of the inverse of the appropriate block coefficient matrix; and $\square \alpha \square$ is a starting Value $=\left(\sigma^{2}{ }_{\mathrm{e}} / \sigma_{\mathrm{a}}^{2}\right)$. It is then why this prior value should be estimated as precisely as possible cause if there are more than one maxima within the parameter space, but if there is only one maxima any starting values would give you the same maxima value. Standard errors of the predicted breeding values were also estimated for each individual as: $\left(S . E_{T A}\right)=d^{j} \sigma_{e}^{2}$ where $d j$ is the diagonal element of the inverse of the appropriate block coefficient matrix that responds to this animal and $\sigma_{\mathrm{e}}^{2}$ is the error variance.

Table 1. APRI improved native rabbits' data Structure

\begin{tabular}{cccc}
\hline Litters & Does & Dams & Sires \\
\hline 192 & 80 & 12 & 9 \\
\hline
\end{tabular}

The relationship coefficient inverse matrix $\left(\mathrm{A}^{-1}\right)$ among animals was as proposed by Korhonen, 1996. MTDFREML program of Boldman et al. (1995) applying the sparse matrix package, SPARSPAK (George and $\mathrm{Ng}, 1984$ ) was adopted for the analysis. A convergence criterion was assumed when the variance of the simplex of the log-likelihood values reached a constant value at a number of digits less than $10^{-}$ 4. This implies that the occurrence of local maxima was checked by repeatedly restarting the analyses until the log-likelihood values did not change beyond the first 4 decimal digits. The MTDFREML evaluates also the proportions of additive genetic effects (heritability; $\mathrm{h}_{\mathrm{a}}^{2}$, permanent environmental effects $\left(\mathrm{c}^{2}\right)$, and error $\left(\mathrm{e}^{2}\right)$.

Animals predicted transmitting abilities $\left(\mathrm{TA}_{i}\right)$; their accuracies $\left(r_{A i}\right)$, and standard errors $S E_{A i}$ :

The (co)variances matrix estimated using MTDFREML analysis is used by the same software for the prediction of breeding values, their accuracies $\left(\mathrm{r}_{\mathrm{Ai}}\right)$, and standard errors $\mathrm{SE}_{\mathrm{Ai}}$. The accuracies of BLUP for each individual were estimated according to the equation suggested by Henderson (1973):

Accuracy in predicting breeding values is simply an estimate of the correlation between an individual's breeding $(A)$ and phenotypic $(P)$ Values, calculated in animal model applying the formula $r_{A p}=\left(1+F-d^{j} \alpha a\right)^{0.5}$. It is a sort of correlation that quantify the ability to predict individual breeding value from some measure and here this measure is its phenotypic value. It is called also the accuracy of the selection scheme and it is used to select parents. A simple statistics study for all the last parameters were introduced to give an idea of the entire animals', sires', dams' and does' minimum, maximum, average value, range in addition to positive records number, percentage, ranges, minimum, maximum, and average values for all the traits under consideration which could give a large idea of the potential of the population evaluated. Another study of the realized association effect between $\mathrm{TA}_{\mathrm{i}}$; epigenetic and Environmental trends was established and presented in graph forms as follows:

\section{Epigenetic Trend:}

The study of the changes in short-termgenotypic adaptation, amendment and/or reformation of the involved genes' controlling the traits considered caused by mechanisms other than changes in the underlying DNA sequence due to environmental effects (e.g.year-season combinations, 5 classes and parities, four classes)are labeled as "epigenetic trends". Epigenetic trend (as a sort of genetic by environment interaction) were estimated using the method reported by (Hassan et al., 2010 and 2013) adapted from that cited by Legates and Myers (1988). After regressing the BLUP values of the engaged animals across the different classes of the insinuated environmental situations using SAS merge statement (SAS, 2003), epigenetic trends are typically calculated as the deviation of the mean of the BV's of the particular group of animals succeeded to reproduce under the environmental situations they were subjected to, from the overall mean of entire group of animals' across all environmental situations' BVs. The resultant output was then plotted in graphs to represent the general trend of the behavior of a specific trait under changeable classes of the fixed effect under consideration (i.e. year season, and parity).

\section{Environmental Trend (ENV):}

Estimated as the result of subtracting TA's of LW values of an animal from its observed phenotypic values of the same traits, all as deviations from the overall means of the whole tested rabbit population environmental divergences. The resultant Litter weight (ENV_LW) values are regressed matching their respective year-season combinations and parity effects as done with the epigenetic trends. Thereafter, they evaluated the same way done with epigenetic trends.

\section{RESULTS AND DISCUSSION}

Means and coefficients of variation of uncorrected records, and Least Square means:

Overall actual means of LW traits in APRI rabbits, standard deviations and coefficients of variation $(\mathrm{CV} \%)$ during the suckling period are 
presented in table (20) for data comparing purposes. Means of litter weight traits (LWB, LW21 and LWW) in this study were within the ranges reviewed in most of the Egyptian studies (Azoz and El-Kholy (2006) on Bauscat rabbits, Kishk et al. (2006), Iraqi and Youssef (2006), while, it was higher than Abdel-Kafy et al. (2012). Coefficients of variability (CV \%) ranged from 31.29 to $36.23 \%$ for litter weight traits. The eminent data variability may reveal that new APRI line rabbits have a relatively substantial variability and it could possibly constitute a rich genetic resource to work upon (which was relatively higher than that for Baladi Black rabbits in the CV \% of LW traits. In the study on Baladi Black rabbits done by AbdelKafy et al. (2012), they reported that such native breed of rabbits with its high performance is ready to be given more attention for genetic improvement.

\section{Parity (P) and Year-season combinations effect (YS):}

Parity (P) and Year-season (YS) combinations (Table 3) had generally no significant effect on most litter weight traits, except that for the significant effect shown by YS on LWW and by parity on only LWB. ElMeghawry (1997) showed a significant effect of parity on LSW. Parity and year-season combinations effects in our study showed inconsistent and no significant source of variation in most litter weight traits. This may be due to the changes in physiological efficiency of the doe with advance of age. These agreed with results of El-Raffa et al. (1997) and Afifi and Khalil (1990).

Table 2. Overall Mean \pm SD, standard deviations (SD) and coefficients of variability (CV \%) of litter weights at LWB, LW21 and LWW for the APRI rabbits

\begin{tabular}{lccc}
\hline Trait & Overall Mean & SD & CV \\
\hline LWB & 0.38 & 0.12 & 31.29 \\
LW21 & 1.52 & 0.48 & 31.55 \\
LWW & 2.67 & 0.97 & 36.23 \\
\hline
\end{tabular}

Table 3. Least Square means, LS-Mean (+ SE) of litter weights at birth; 21 days and weaning at 5 wks. (LWB, LW21 and LWW) for the APRI rabbits

\begin{tabular}{lccccccc}
\hline & \multirow{2}{*}{ No. } & \multicolumn{2}{c}{ LWB } & \multicolumn{2}{c}{ LW21 } & \multicolumn{2}{c}{ LWW } \\
\cline { 3 - 8 } & & LS-Mean & SE & LS-Mean & SE & LS-Mean & SE \\
\hline$\mu$ (overall Mean) & 192 & 0.40 & 0.01 & 1.42 & 0.08 & 2.44 & 0.12 \\
\hline Parity & 85 & 0.35 & 0.02 & 1.41 & 0.10 & 2.39 & 0.17 \\
1.st & 44 & 0.40 & 0.02 & 1.45 & 0.12 & 2.54 & 0.22 \\
2nd. & 32 & 0.44 & 0.02 & 1.45 & 0.14 & 2.47 & 0.25 \\
3rd. & 31 & 0.40 & 0.03 & 1.35 & 0.14 & 2.38 & 0.27 \\
4th. & 20 & 0.38 & 0.03 & 1.30 & 0.17 & 2.13 & 0.32 \\
\hline Year-Season (YS) & 33 & 0.40 & 0.02 & 1.44 & 0.14 & 2.52 & 0.25 \\
83 (Yr1-Summer) & 31 & 0.41 & 0.02 & 1.62 & 0.13 & 2.98 & 0.24 \\
84 (Yr1-Autumn) & 108 & 0.40 & 0.01 & 1.31 & 0.09 & 2.14 & 0.15 \\
91 (Yr2-Winter) & \multicolumn{6}{c}{ Not sig } \\
92 (Yr2-Spring) & \multicolumn{7}{c}{ Nig } \\
\hline
\end{tabular}

\section{Variance component estimates ( $\sigma 2)$ :}

An inconsistent trend was observed in APRI rabbits, for $\mathrm{LW}$ additive genetic variance $(\sigma 2 \mathrm{~A}$; diagonal elements) as values and as proportion of the total observed variance (Table 4).Though, seemed generally to be age dependent and curvilinear, its ratios increased as 21 days post kindling and decreased thereafter at weaning at5wkspost-kindling. However; litter traits as fitness and transitional traits are expected to be marginal with consumed additive genetic variance due to that they are being continually subject to natural selection.

In this respect, the phenotypic variance, (diagonal elements) of litter weight traits show a consistent trend of being age dependent and increased as the period after kindling increased (Table 4).
Permanent environment of LW traits, was found to be very low in magnitude. Conversely, Youssef (2003) reported that litter weight traits are greatly affected by the additive genetic and maternal effects. In this respect, Khalil (1987) reported that the low percentages of sire variance component reflect the large environmental component of variance associated with the doe during kindling and raising of its litters to weaning. He also added that since milk production and subsequently litter gains are of the fitness traits and are influenced by litter size, it is supposed that the additive variance has been diminished through long term natural selection.Though variance component estimates differed among Egyptian rabbit populations, estimated values suggest that genetic selection for milk production would be feasible in these populations. 


\section{Heritability estimates:}

Heritability estimates using REML method for LW traits in APRI rabbits, were relatively low, from $0.13-0.14$, table 3 . These estimates were comparable with those ranges reported by El Raffa (2000), Baselga and Garcia (2002), Youssef (2003), Nofal et al. (2002), Iraqi and Youssef (2006), Gad (2007), Gharib et al.(2008) and Iraqi (2008). These low h2 figures may be attributed to the consumption of the additive genetic variance due to natural selection which consequently led to inflated non additive genetic and environmental factors (i.e. constitute the major source of variation reported herein for those traits). In this respect, Khalil (1987) concluded that environmental conditions and non-additive genetic effects play a large role in doe litter traits in rabbits. Therefore, such diminished estimates for heritability for these traits may reveal higher non additive genetic effects for all studied litter traits. Such low heritability traits do not support individual selection and therefore, family and within family selection could play a role especially with the presence of genetic evaluation for each animal (i.e. BLUP). Also crossbreeding it too often associated with heterosis and performance improvement in such fitness traits. Marker assisted selection would be the preferred technique but on the other hand it is still very expensive and not veritably available under the Egyptian condition.

Indirect selection for litter traits from its component traits as a consequence of their nature as composite traits could be an alternative solution key especially in the positively high correlated traits.

Table 4. Additive genetic ( $\sigma 2 \mathrm{~A})$ and phenotypic co-variance, percentages of permanent environment as proportion of the phenotypic variance of litter weight traits at $L W B$, LW21 and LWW for APRI rabbits

\begin{tabular}{|c|c|c|c|c|c|c|c|c|c|}
\hline & \multicolumn{3}{|c|}{$\begin{array}{l}\text { Additive genetic ( } \sigma 2 \mathrm{~A}) \\
\text { variance }\end{array}$} & \multicolumn{3}{|c|}{$\begin{array}{l}\text { Phenotypic Variances } \\
\text { And Covariances }\end{array}$} & \multicolumn{3}{|c|}{$\begin{array}{c}\text { \% Uncorrelated Random } \\
\text { Effects }\end{array}$} \\
\hline & LWB & LW21 & LWW & LWB & LW21 & LWW & LWB & LW21 & LWW \\
\hline LWB & $\begin{array}{c}0.005 \\
16.70 \%\end{array}$ & 0.012 & 0.040 & 0.031 & 0.111 & 0.238 & 0.200 & 0.210 & -0.010 \\
\hline LW21 & 0.012 & $\begin{array}{c}0.026 \\
40.30 \%\end{array}$ & 0.090 & 0.111 & 0.645 & 1.226 & 0.210 & 0.002 & 0.970 \\
\hline LWW & 0.040 & 0.090 & $\begin{array}{c}0.310 \\
11.48 \%\end{array}$ & 0.238 & 1.226 & 2.730 & $\begin{array}{c}- \\
0.010 \\
\end{array}$ & 0.970 & 0.008 \\
\hline
\end{tabular}

\section{Genetic correlation:}

All estimates of genetic correlations among litter weights (Table 5) were high and positive. Thus we may build the strategy on selection criteria on these traits. Values of genetic correlations extracted from animal model procedures are of limited practical usefulness and to some extent hard to elucidate and unreliable. The covariance yielded by multi trait animal model is in most cases doubtful and debatable and did not clearly differ from zero especially when the number of traits involved in the analysis exceeds from one to two. A comparable conclusion has been reached at by Luiting and Urf, 1991 who determined that an alternative method is acceptable in a breeding program if no reliable estimates of genetic correlations are available.

This is why an alternative study of the correlations among the resultant transmitting ability, values and ranks, is from one point of view indisputable and undeniable. However, when such study is to be done (i.e. estimating correlations among the resultant transmitting ability), it is foreseeably better to be a resultant from single trait animal models analysis (a paradigm not used in this paper).

\section{Animal Evaluation:}

Transmitting abilities (TA's); Accuracies (rAP) and Standard error (SEAi):

Only the phenotypic value of individuals can be directly measured, but it is the breeding values that determine their influence on the next generations. Estimates of APRI rabbits transmitting abilities (Statistically BLUP's), their accuracies (rAP) and Standard errors (SEAi) for litter weights traits generated from the animal model analysis are presented in table 6. Selection emphasis can be applied differently to various ancestors. Generally, fewer males are needed for reproduction purposes than females. Thus, producers can be stringently strict about their requirements for males than for females. Only the very best (top 1\%) sires and dams will be used to produce future sires in most species. The next females, however' will be offspring of sires in the top $25 \%$ of the species and of dams in the top $75 \%$ of the population. This is because nearly all females are kept for breeding purposes, while most males are culled or sent to market at an early age. These figures can vary inconsequentially from one species to another. 
Table 5. Heritabilities (h2, on diagonal) and genetic correlations (below diagonal), permanent environment and the error as proportion of the phenotypic variance of litter weight traits at birth; 21 days and weaning at 6 wks. for rabbits

\begin{tabular}{cccccccc}
\hline \multicolumn{3}{c}{ Heritabilities and genetic correlations } & \multicolumn{5}{c}{ Environmental as a proportion of total variance } \\
\hline \multicolumn{2}{c}{ LWB } & LW21 & LWW & & LWB & LW21 & LWW \\
\hline LWB & 0.170 & & & LWB & 0.630 & & \\
LW21 & 0.900 & 0.040 & & LW21 & 0.890 & 0.960 & \\
LWW & 9.000 & 0.990 & 0.110 & LWW & 0.910 & 0.930 & 0.880 \\
\hline
\end{tabular}

Table 6. Transmitting abilities (TA, Minimum, Maximum, and range); Standard Errors (SEAi) and Accuracies (rAi) of transmitting abilities in addition to positive records of litter weight traits at LWB, LW21 and LWW for APRI

\begin{tabular}{|c|c|c|c|c|c|c|c|c|c|c|c|c|c|}
\hline & & \multicolumn{3}{|c|}{ All Data } & \multicolumn{3}{|c|}{ Does Data } & \multicolumn{3}{|c|}{ Dams Data } & \multicolumn{3}{|c|}{ Sires Data } \\
\hline & & $\underset{\Xi}{\stackrel{\square}{F}}$ & $\frac{N}{\stackrel{N}{\stackrel{N}{2}}}$ & 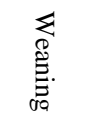 & $\stackrel{\square}{\Xi}$ & $\frac{N}{\sim}$ & 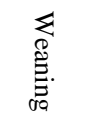 & $\stackrel{\square}{\leftrightarrows}$ & $\frac{N}{\stackrel{N}{\stackrel{N}{2}}}$ & $\underset{\infty}{\stackrel{8}{\Xi}}$ & $\stackrel{\varpi}{\rightleftarrows}$ & $\frac{N}{\stackrel{N}{0}}$ & 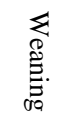 \\
\hline No. & & & 91 & & & 80 & & & 12 & & & 9 & \\
\hline \multirow{3}{*}{$\begin{array}{c}\text { MAX } \\
\text { values of }\end{array}$} & TA & 0.06 & 0.134 & 0.459 & 0.06 & 0.134 & 0.459 & 0.019 & 0.043 & 0.147 & 0.022 & 0.049 & 0.168 \\
\hline & SE & 0.07 & 0.16 & 0.56 & 0.06 & 0.14 & 0.49 & 0.07 & 0.16 & 0.56 & 0.07 & 0.16 & 0.54 \\
\hline & $\mathrm{rAi}$ & 0.83 & 0.83 & 0.84 & 0.84 & 0.83 & 0.84 & 0.84 & 0.83 & 0.84 & 0.77 & 0.77 & 0.77 \\
\hline \multirow{3}{*}{$\begin{array}{c}\text { MIN } \\
\text { values of }\end{array}$} & TA & -0.092 & -0.206 & -0.708 & -0.092 & -0.206 & -0.708 & -0.072 & -0.161 & -0.555 & -0.083 & -0.186 & -0.64 \\
\hline & SE & 0.04 & 0.09 & 0.31 & 0.04 & 0.09 & 0.31 & 0.04 & 0.09 & 0.31 & 0.05 & 0.1 & 0.35 \\
\hline & $\mathrm{rAi}$ & 0.00 & 0.00 & 0.00 & 0.49 & 0.49 & 0.49 & 0.00 & 0.00 & 0.00 & 0.26 & 0.26 & 0.26 \\
\hline \multirow{3}{*}{ Range of } & TA & 0.152 & 0.34 & 1.167 & 0.152 & 0.34 & 1.167 & 0.091 & 0.204 & 0.702 & 0.105 & 0.235 & 0.808 \\
\hline & SE & 0.03 & 0.07 & 0.25 & 0.02 & 0.05 & 0.18 & 0.03 & 0.07 & 0.25 & 0.02 & 0.06 & 0.19 \\
\hline & $\mathrm{rAi}$ & 0.84 & 0.83 & 0.84 & 0.35 & 0.34 & 1.184 & 0.84 & 0.83 & 0.84 & 0.51 & 0.51 & 0.51 \\
\hline \multicolumn{14}{|c|}{ Positive Records } \\
\hline Number & & 25 & 23 & 23 & 22 & 20 & 20 & 5 & 4 & 4 & 2 & 2 & 2 \\
\hline$\%$ & & 27.47 & 25.47 & 25.47 & 27.50 & 25.00 & 25.00 & 41.67 & 33.33 & 33.33 & 22.22 & 22.22 & 22.22 \\
\hline \multirow{2}{*}{ TA } & Min & 0.00 & 0.00 & 0.00 & 0.00 & 0.00 & 0.00 & 0.02 & 0.04 & 0.12 & 0.00 & -0.01 & -0.02 \\
\hline & Range & 0.06 & 0.134 & 0.458 & 0.06 & 0.134 & 0.458 & 0.003 & 0.007 & 0.024 & 0.024 & 0.054 & 0.184 \\
\hline SE & & 0.01 & 0.03 & 0.11 & 0.00 & 0.01 & 0.04 & 0.02 & 0.05 & 0.19 & 0.00 & 0.01 & 0.03 \\
\hline $\mathrm{rAi}$ & & 0.09 & 0.08 & 0.09 & 0.09 & 0.08 & 0.09 & 0.04 & 0.03 & 0.04 & 0.07 & 0.07 & 0.07 \\
\hline
\end{tabular}

From results presented in table 6 , it is obvious that the minimum and maximum values as well as difference between them (ranges) of TA are age dependent and they increased as the period post kindling lengthened till weaning at 5 wks of doe's bunnies age. On the contrary, the number of positive records though age dependent but they decreased as the period post kindling lengthened. Fortunately, the percentage number of positive records $(\mathrm{n}+)$ for the whole, does' and dams' data didn't get behind or set down the border of $25 \%$ (which is the maximum expected number of replacement females). However and as for sires, the situation is different since they were at the border of ( 2 sires) $22 \%$. Putting in mind that the replacement rate of sires is far less from that of dams, these figures could be convenient if breeding plan is about elevating the population levels of litter weights. The trend consistency of positive records may reveal that there may be a positive association between the traits on the animals of positive records, which will be dealt with in the part of association studies between BLUP estimates of litter weight traits. The later conclusion, if true will help the breeders of these line rabbits to make their decision of selecting early in bunnies life based on the birth BLUP values. This of course would reduce the generation intervals and cuts down the breeding costs. Nevertheless, the SEAi values are relatively high at early ages which may impose difficulty of making such a decision of early selection but fortunately again the reliability or accuracies (rAP) of the higher records are outstandingly high (not presented in tables).In this respect the higher the rAP values, the more reliable is the BLUP's and the more certain the breeder is about the results of the selection decision. Generation interval is the average age of a sire or dam when a potential replacement progeny is born. Shortening the generation interval generally results in faster genetic change. Generation intervals depend largely on reproductive capacity of the species, but any technology that allows the breeding value of an animal to be estimated earlier in life will shorten the generation interval. Reproductive capacity of a species may be changed with any technology helps to get more offspring per mating, to use fewer males or females, or to reduce the length of time to age at first breeding. 
However, sires TA estimates are superior when compare with does and dams' data. This could be advantageous yet again, since sires constitute almost $50 \%$ of the hereditary of the next generation of animal and needless to say this native rabbit populations. The later presumption coupled with an elevated selection intensity pressure of the sires may reveal that the additive genetic makeup of the next generation of this line rabbit population is expected to be larger than that would think of based on dams', does' or whole population data (i.e.is expected to yield a greater LW traits selection response). In this respect, El-Raffa (1997) reported that differences between minimum and maximum values of the top $25 \%$ sire breeding value estimates are the backbone for any planned selection strategy to improve economic traits.

\section{Epigenetic Trend (EGT):}

The Character of economic importance in animals which normally show continuous variation, are of immense concern to both breeders and producers. Such characters are controlled by a large number of genes, each in the infinitesimal, theory having small similar and supplementary effect on the character. The cumulative effects of such genes, coupled with environmental effects produce continuous variation in the phenotypic values of individual. To optimize genetic improvement, the EBVs can be used to determine which male to breed to each female, such that the offspring are comprised of the highest possible average breeding value. Breeding strategies are concerned with the design of an efficient breeding program that maximizes genetic change under a certain set of conditions over the next few generations. What happens when conditions are changed or when restrictions are relaxed! Breeding strategies require a comprehensive understanding of such nonconforming recalcitrant, but still frequent, situations as well as the biology of the species or the production system.

Epigenetic trends which are estimated as a deviation from the overall BLUP values' mean of the whole tested rabbit population for Litter weight (EPGLWt) traits as affected by parity and year- season combinations were illustrated in figures 1 and 2 . Results shown in figures 1 , revealed that all LW traits' genetic change with Parity effects gave generally equivalent and comparable patterns (the first parity of all ages gave negative trends while the remainder parities gave positive trends), which may generally reveals analogous related (genotype $\mathrm{X}$ environment) interaction in APRI rabbits. The high APRI litter weight epigenetic trend at the second and third parities is apparently due to substantial compatibility between physiological, reproductive maturity, development. Rabbit better performance is reached at these specific parities with slight differences between rabbit breeds (Hassan et al., 2010 and Hassan et al., 2013).

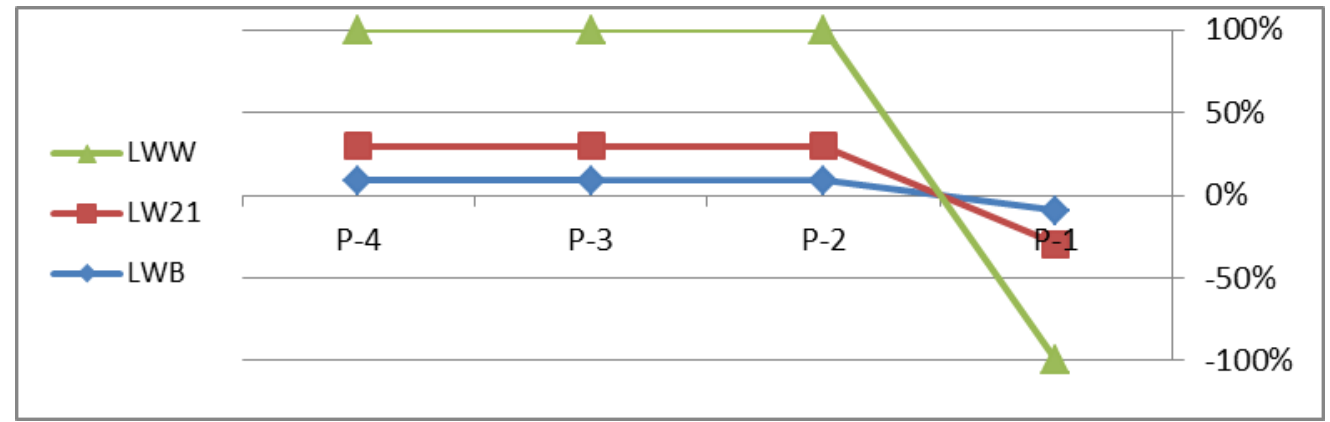

Fig. 1. Epigenetic trend of BLUP values of LW traits regressed against parity

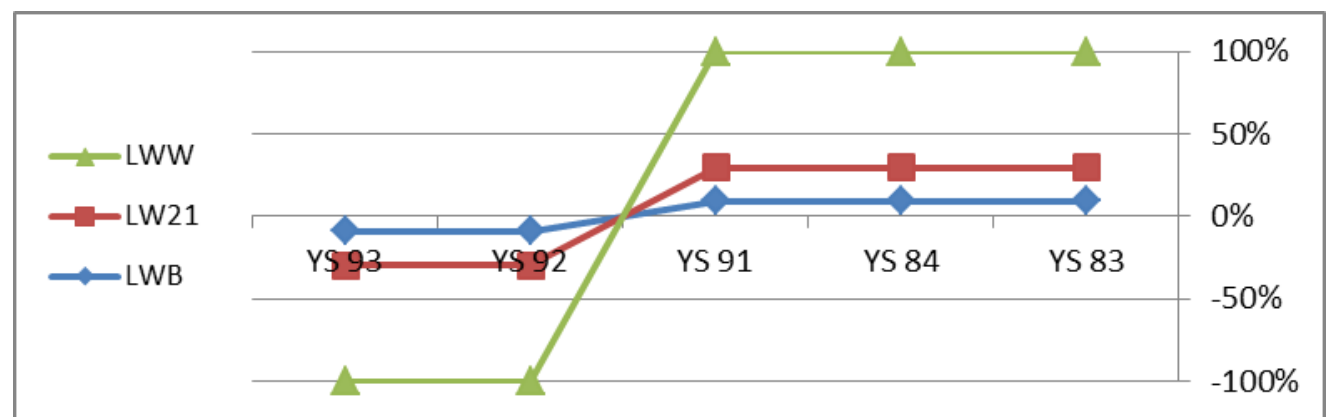

Fig. 2. Epigenetic trend of BLUP values of $L W$ traits regressed against Year-season

Results in figure (2), revealed that all LW traits' genetic change with Year-season (YRS) effects once again gave a comparable pattern
YRS 93, (2nd Year-Summer) gave a step-by-step progressive negative trends while all the rest gave approximately no or positive trends), which 
may possibly divulges comparable or equivalent (genotype $\mathrm{X}$ environment) interaction in APRI rabbits. The prominent epigenetic trend is that for YRS 83 (1st Year-summer). The expected explanation for the former situation is that this performance is in conformity with the high loss of bunnies due to hot stress in summer months. The positive (high) LW epigenetic trend during autumn and winter is evidently comprehensible as the animals are exploiting the favorable proximate conditions and have the favorable fodder diets like clover and/or alphalpha fresh hay.

\section{Environmental Trend (Env_LW):}

If all the variations are attributable to environment, selection of phenotypically superior individuals would not result in any alteration in the next generation. Environment trends are calculated by subtracting BLUP values of LW traits from the phenotypic values of the same traits. The resultant values are then treated the same as done before with epigenetic trends (i.e. regressing against Year-Season, Yr_S and parity, P) to get the environmental changes due to both effects (i.e. Yr_S and P).Litter weight (Env_LW) traits as affected by Year-season combinations and parity were illustrated in figures 3 and 4 . The two graphs revealed that Litter weights of the tested rabbit population have an obvious trend that the changes due to parity are more drastic than that due to yearseason combinations effects. Nevertheless, across evaluated ages as the litters becomes older the changes seems to get more profound and radical making it obvious to divide the preweaning period as to the sensitivity to environmental situations into early and late preweaning periods. While at the early pre-weaning period the suckling mothers play a role in smoothing the sensitivity to the difference in environments, the late pre-weaning period the individual capability of the bunnies appear as more reflection and meticulousness to environmental situations.
As regard to Litter weights environmental by Year-season combinations changes, Fig. 4 showed that litter weight traits of the tested APRI rabbit population have a positive environmental trend during the first and the second season of the second year (February till June), meaning that the effects of environment was highly favorable and propitious during these months, also it may be due to the miscellaneous factors that cannot be accounted for in the model, thus these animals perhaps did not express themselves as a result of inadequate rearing environment especially feeding and slight infections around the high year temperature. However these traits decreased sharply during the third season, (first year-from September through November). Such detected adverse or undesirable environmental effect during autumn (negative trend) may be due to extended summer hot climate stress or to the lack of green fodders the downgrade quality of elongated-stored ones the problem that is distinctive to the Egyptian rabbit production situations.

Negative environmental trend in the third season (September till November-Figure 4), was observed. The high LW performance of the tested population versus environment trends are evidently comprehensible as the animals are, in these periods, exploiting the favorable proximate conditions and also the favorable abundant fodder diets like alphalpha.

As for environment $\mathrm{X}$ parity interaction, data of environment trends presented in Fig. (3), The effects of environment was low and not clear for LWB in the 1st, 2nd, 3rd and 4th parities, otherwise, it started to have negative trends especially in the 1 st and 4th ones. In case of LW21 and LWW, Positive environment trend seems to concentrate in the 2 nd and 3 rd parities, seemingly because at the 1st parity Animals are in their first production season with their reservoirs unexhausted; or because does may have an adequate rearing and managerial conditions.

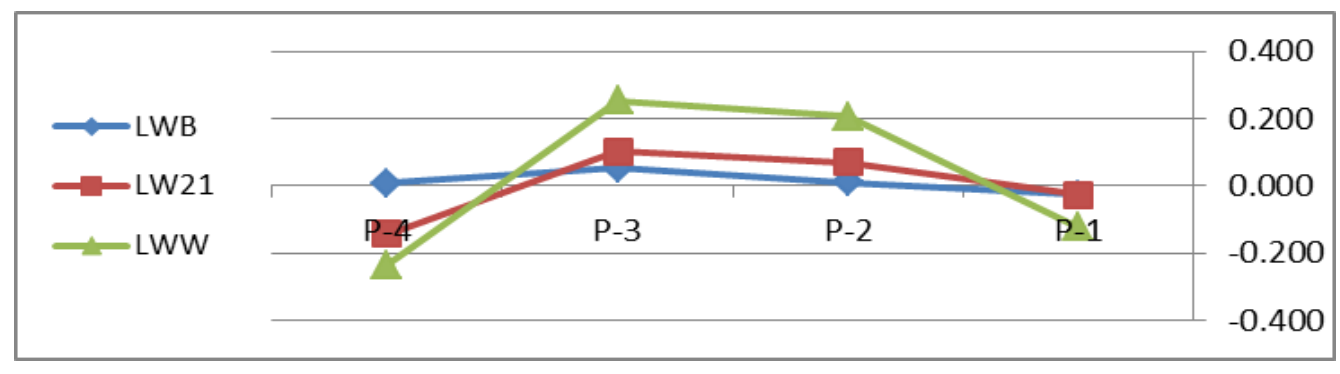

Fig. 3. LW traits environmental values trend as regressed against parity 


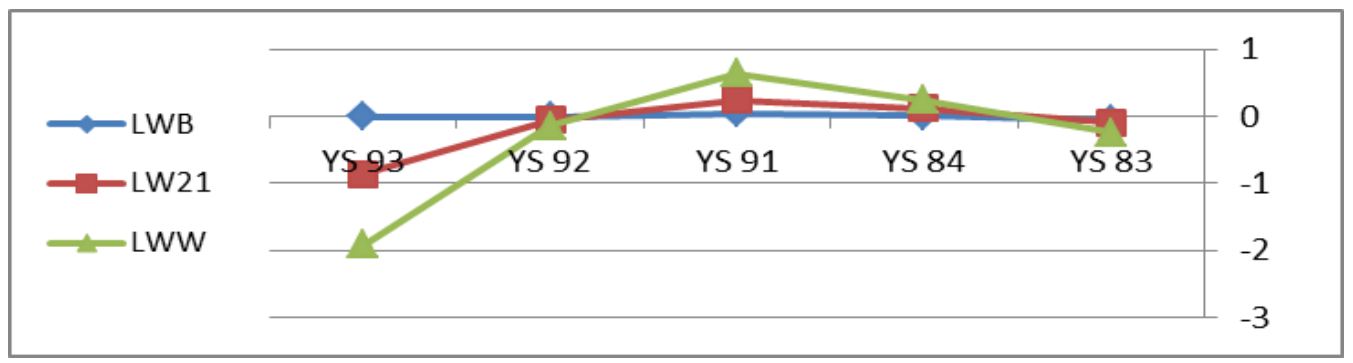

Fig. 4. LW traits environmental values trend as regressed against Year-season

\section{CONCLUSION}

Current data revealed that such native breed of rabbits with its high performance is ready to be given more attention for genetic improvement through selection (especially with the large additive component of variance at weaning) and crossbreeding with sensibly and conscientiously chosen standard breeds to produce resourceful broiler rabbits especially with the large components of non-additive genetic component of the studied litter weight traits. However, backcrossing with the founder breeds either the locale to improve quite a bit the acclimatization to Egypt environment or to the standard to increase the adapted to hot weather environment and percentage of blood contribution and in both cases to stabilize the performance against segregation

\section{REFERENCES}

Abdel-Ghany, A. M.; G. E. Y. Attalah, A. M. Farid and M. G. Gharib, 2007. Crossbreeding Effects of Weaning and Post-Weaning Body Measurements of Bauscat and Baladi Red Rabbits. Agriculture Research Journal, Suez Canal University, 7(2): 1-7.

Abdel-Kafy E.M, Hassan N.S., Morsy W.A., Ali Kh.A.A., El-Sawy M.A., Hassanein M.N.F., Z.A.M. Sabra, 2012. Genetic parameters of litter traits in a local baladi black rabbit in Egypt 10th World Rabbit Congress September 3 - 6, 2012- Sharm El-Sheikh Egypt, 37-41.

Afifi, E.A. and, M.H. Khalil, 1990. Observations on purebred and crossbred litters of Giza White and Grey Giant Flander rabbits in Egypt. J. of Applied Rabbit Research, 12: 273-277.

Azoz A.A. and K.H. El-Kholy, 2006. Reproductive performance and blood constituents of V-line and Bauscat Female rabbits under middle Egypt conditions. Egyptian J. of rabbit science, 16 (1): 139160.

Baselga, M. and M. L. Garcia , 2002. Evaluating the Response to Selection in Meat Rabbit Programs. The $3^{\text {rd }}$ Scientific Conference on
Rabbit Production in Hot Climates, Hurghada, Egypt 8-11 October, 1-10-2002.

Boldman, K. G., L. A. Kriese, L. D. Van Vleck, C. P. Van Tassell and S. D. Kachman , 1995. A Manual for Use of MTDFREML. A Set of Programs to Obtain Estimates of Variances and Covariances [DRAFT]. U.S. department of Agriculture, Agricultural Research Service, USA.

Duncan, D.B., 1955. Multiple Range and Multiple F-test. Biometrics, 11: 1-42.

El-Raffa A. M., M. K. Shebl, M.A. Kosba and M.H. Khalil, 1997. Sire and Dam transmitting abilities for litter size traits in three lines of rabbits raised in high intensive system of production. Egyptian J. of rabbit science, 7 (2): 67-79.

El-Raffa, A. M., 2000. Animal Model Evaluation of $\mathrm{V}$ Line Rabbits Raised Under Egyptian Condition. Egyption Journal of Rabbit Science, 10 (I): 75 -82.

Estany J, Baselga M, Blasco A and J Camacho, 1989 Mixed model methodology for estimation of genetic response to selection in litter size in rabbits. Livestock Production Science 21: 67-75

Estany J., Baselga M., Blasco A., J. Camacho, 1989. Mixed model methodology for the estimation of genetic response to selection in litter size of rabbits. Livest. Prod. Sci., 21: 67-76.

Falconer, D.S. 1981. Introduction to Quantitative Genetics. 2nd Edition. Longman, London.

Fatmah M. A B., 2014. Genetic Study for Some Body Measurements and Its Relationship with Some Productive Traits in Rabbits. Ph.D. Thesis, Faculty of Agriculture, Tanta University, Egypt.

Gad, S.O.A., 2007. Genetic Analysis for Productivity of Gabali Rabbits Raised in the North-Western Coast of Egypt. Ph.D. Thesis, Faculty of Agriculture, Moshtohor, Zagazig Univ., Banaha, Egypt.

Gharib, M. G., G. E. Y. Attalah, A. Farid, M. A. Aboul Hassan and M. M. S. Mabrouk , 2008. Evaluation of Some Genetic Parameters and Permanent Environmental Effects for Some Maternal Traits in Two Breeds of Rabbits. Egyptian J. of Rabbit Science, 18 (2): 145156. 
Hassan, N. S.; Abdel-Ghany A. M.; Hanan H. Ghanem; M. A. El-Shennawy and Mona M. Ghaly, 2013. Genetic evaluation of the native Baladi Black rabbits under North Deltaweather of Egypt using Animal Model procedure. A: Doe litter traits. Journal of Animal, Poultry \& Fish Production, Suez Canal University, Vol (1), 2013: 13-22.

Hassan, N. S., A. Farid, A. M. Abdel-Ghany, Sabri, H. M. Ahmed, E. G. and Mona M. Ghaly, 2010: Epigenetic Trend of Milk Yield and Litter Gain Traits in Californian Rabbits. The $6^{\text {th }}$ International Conference on Rabbit Production in Hot Climates, 1-4 Feb. Assiut., Egypt.

Henderson, C. R., 1973. Sire Evaluation and Genetic Trends. In: Proc. Anita. and Genet. Symp. In Honor of J. L. Lush. pp 10 - 41. Amer. Soe. Anim. Sci., Champaign, IL.

Iraqi, M. M. and Y. M. K. Youssef, 2006. Genetic analysis for milk production traits in New Zealand White rabbits raised in Egypt. Egyptian Journal of Rabbit Science 16(1):113.

Iraqi, M. M., 2008. Estimation of Heritability and Repeatability for Maternal and Milk Production Traits in New Zealand White Rabbits Raised in Hot Climate Conditions, Livestock Research for Rural Development 20 (8) 2008.

Khalil, M.H., J.B. Owen, and E.A. Afifi, 1987. A genetic analysis of litter traits in Bauscat and Giza White rabbits. Anim. Prod., 45: 123:134

Khalil, M.H.; E.A. Afifi,; Y.M.K. Youssef, and A.F. Khadr, 1995. Heterosis, Maternal and Direct Genetic Effects for Litter. Reference 291 Performance and Reproductive Intervals in Rabbit Crosses. World Rabbit Sci., 3 (3), 99-105.

Kishk, W.H., H.A. Khalil, A.M. Hassanein and M.A. Ayoub, 2006. Physiological, Reproductive and Productive traits of New Zealand White rabbit does as affected by natural mating time. Egyptian J. of rabbit science, 16 (2): 223-232.
Korhonen, T., 1996. The Dairy Cattle Evaluation of 1996.

http://www.mloy.fi/faba/blup/blup1.htmlblup1.ht $\mathrm{ml}$

Legates, J. E. and R. M. Myer, 1988): Measuring Genetic Change in a Dairy Herd Using a Control Population. J. Dairy Sci., 71(4):10251033.

Luiting P. and E. M. Urf, 1991. Residual feed consumption in laying hens. 1. Quantification of Phenotypic Variation and Repeatabilities. Poultry Science, 70: 1655-1662.

Nofal, R.Y., A. M. Abdel-Ghany and K. Saleh, 2002. Best Linear Unbiased Prediction (BLUP) on Some Litter Traits and Masculinity Rate of New Zealand White Rabbits Under Egyptian Conditions. The 3rd Scientific Conference on Rabbit Production in Hot Climates, Hurghada, Egypt 8-11 October, 127-137.

SAS., 2003. SAS Online Doc 9.1.3. SAS Institute Inc., Cary, NC, USA.

Searle, S. R., 1989. Variance Component Some History and a Summary Account of Estimation Methods. Anim. Breed. Genetics. 106: 129

Youssef Y.K., M.M. Iraqi, A.M. El-Raffa, E.A. Afifi, M.H. Khalil, M.L. García, M Baselga., 2008. A joint project to synthesize new lines of rabbits in Egypt and Saudi Arabia: emphasis for results and prospects. In Proc.: 9th World Rabbit Congress, 10-13 June, 2008. Verona, Italy. 1637-1642.

Youssef, M.K., 1992. Productive performance of purebred and crossbred rabbits. M.Sc. Thesis, Fac. Agric. Moshtohor, Zagazig Univ., Banha Branch, Egypt.

Youssef, Y. M. K.; M. M. Iraqi and N. S. Hassan, 2003. Heritability, Repeatability and Permanent Environmental Effect for Litter Traits in New Zealand White and Baladi Red Rabbits. Annals of Agriculture Science, Moshtohor, 41(4):1459-1469. 
المقاييس الوراثية لصفات وزن الخلفة لأرانب الأبرى المصرية

ناجى سعيد حسن'، أحمد محمود عبد الغنى'، هانئ محمد صبرى'

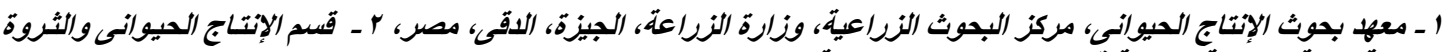

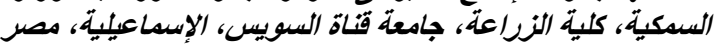

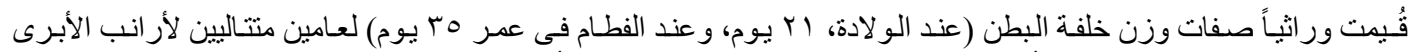

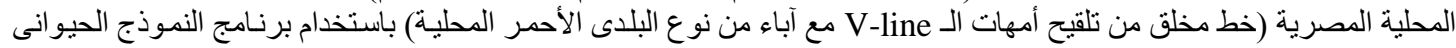

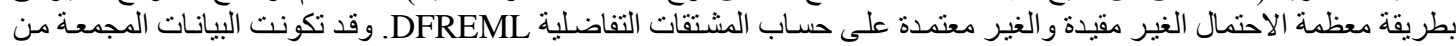

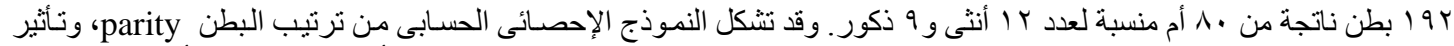

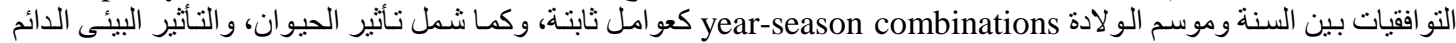
كعو امل عشو ائية التئية

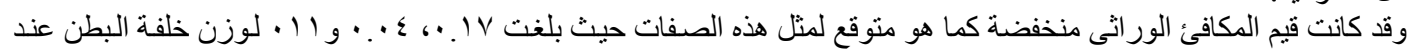

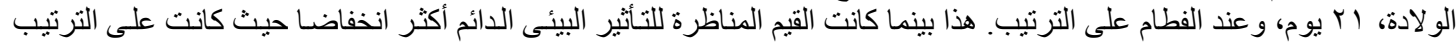

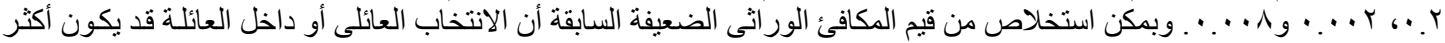

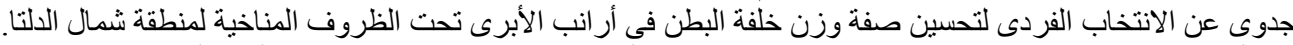

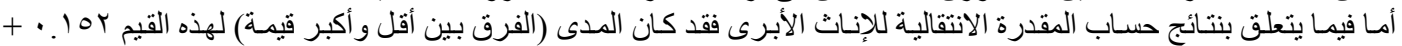

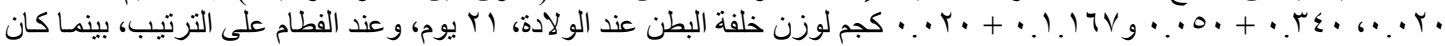

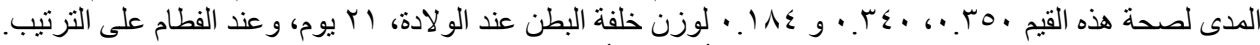

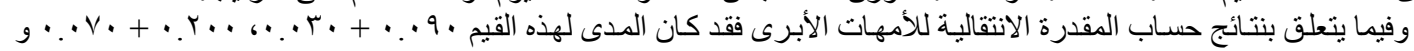

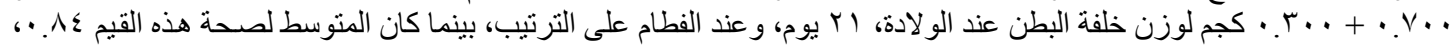

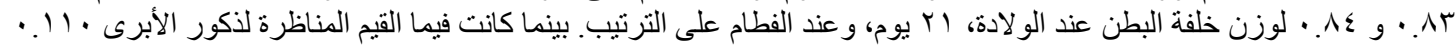

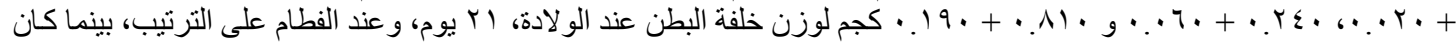

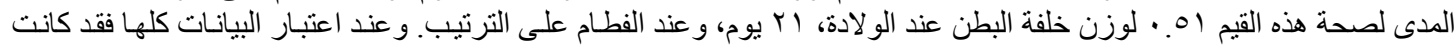

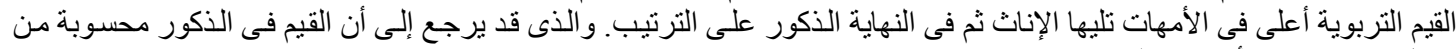

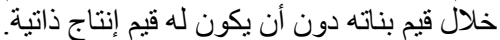

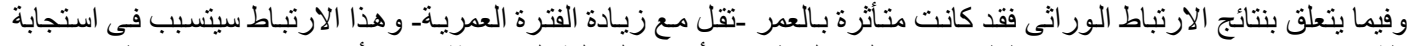

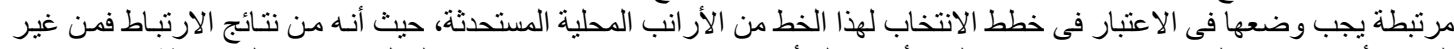

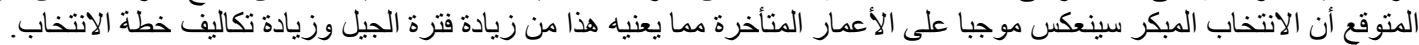

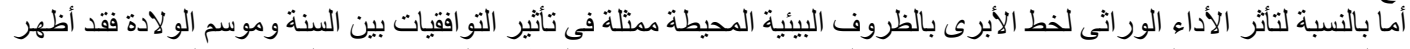

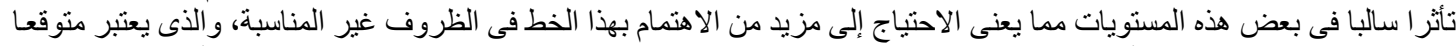

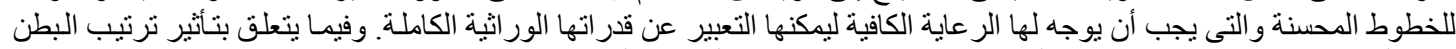

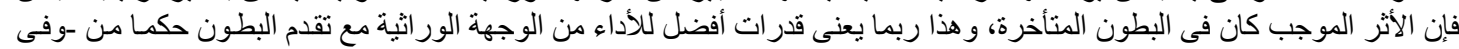

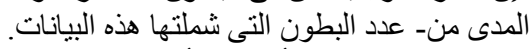
الكلمات الدلالية:خط الأرانب الأبرى، وزن خلفة البطن، تقديرات مكونات التباين و المكافئ الور اثيين، تأثتر الأداء الور اثى بالظروف 

Egyptian J. Anim. Prod., 52, Suppl. Issue, April (2015):137-147

Issued by The Egyptian Society of Animal Production 